THURSDAY, APRIL 3, 1873

\section{ORIGIN OF CERTAIN INSTINCTS}

7 HE writer of the interesting article in NATURE 1 of March 20 doubts whether my belief "that many of the most wonderful instincts have been acquired, independently of habit, through the preservation of useful variations of pre existing instincts," means more than " that in a great many instances we cannot conceive how the instincts originated." This in one sense is perfectly true, but what I wished to bring prominently forward was simply that in certain cases instincts had not been acquired through the experience of their utility, with continued practice during successive generations. I had in my mind the case of neuter insects, which never leave offspring to inherit the teachings of experience, and which are themselves the offspring of parents which possess quite different instincts. The Hive-bee is the best known instance, as neither the queen nor the drones construct cells, secrete wax, collect honey, \&c. If this had been the sole case, it might have been maintained that the queens, like the fertile females of humble-bees, had in former ages worked like the present neuters, and had thus gradually acquired these instincts; and that they had ever afterwards transmitted them to their sterile offspring, though they themselves no longer practised such instincts. But there are several species of Hive-bees (Apis) of which the sterile workers have somewhat different habits and instincts, as shown by their combs. There are also many species of ants, the fertile females of which are believed not themselves to work, but to be served by the neuters, which capture and drag them to their nests; and the instincts of the neuters in the different species of the same genus are often different. All who believe in the principle of evolution will admit that with social insects the closely allied species of the same genus are descended from a single parent-form ; and yet the sterile workers of the several species have somehow acquired different instincts. This case appeared to me so remarkable that I discussed it at some length in my "Origin of Species ;" but I do not expect that anyone who has less faith in natural selection than I have, will admit the explanation there given. Although he may explain in some other way, or leave unexplained, the development of the wondrous instincts possessed by the various sterile workers, he will, I think, be compelled to admit that they cannot have been acquired by the experience of one generation having been transmitted to a succeeding one. I should indeed be glad if anyone could show that there was some fallacy in this reasoning. It may be added that the possession of highly complex instincts, though not derived through conscious experience, does not at all preclude insects bringing into play their individual sagacity in modifying their work under new or peculiar circumstances; but such sagacity, as far as inheritance is concerned, as well as their instincts, can be modified or injured only by advantage being taken of variation in the minute brain of their parents, probably of their mothers.

The acquirement or development of certain reflex actions, in which muscles that cannot be influenced by the will are acted on, is a somewhat analogous case to that

$$
\text { No. 179-VoL, vir. }
$$

of the above class of instincts, as I have shown in my recently published book on Expression ; for consciousness, on which the sense of utility depends, cannot have come into play in the case of actions effected by involuntary muscles. The beautifully adapted movements of the iris, when the retina is stimulated by too much or too little light, is a case in point.

The writer of the article in referring to my words "the preservation of useful variations of pre-existing instincts " adds "the question is, whence these variations?" Nothing is more to be desired in natural history than that some one should be able to answer such a query. But as far as our present subject is concerned, the writer probably will admit that a multitude of variations have arisen, for instance in colour and in the character of the hair, feathers, horns, \&c., which are quite independent of habit and of use in previous generations. It seems, far from wonderful, considering the complex conditions to which the whole organisation is exposed during the successive stages of its development from the germ, that every part should be liable to occasional modifications: the wonder indeed is that any two individuals of the same species are at all closely alike. If this be admitted, why should not the brain, as well as all other parts of the body, sometimes vary in a slight degree, independently of useful experience and habit? Those physiologists, and there are many, who believe that a new mental characteristic cannot be transmitted to the child except through some modification of that material sub-stratum which proceeds from the parents, and from which the brain of the child is ultimately developed, will not doubt that any cause which affects its develupment may, and often will, modify the transmitted mental characters. With species in a state of nature such modifications or variations would commonly lead to the partial or complete loss of an instinct, or to its perversion; and the individual would suffer. But if under the then existing conditions any such mental variation was serviceable, it would be preserved and fixed, and would ultimately become common to all the members of the species.

The writer of the article also takes up the case of the tumbling of the pigeon, which habit, if seen in a wild bird, would certainly have been called instinctive; more especially if, as has been asserted, it aids these birds in escaping from hawks. He suggests that it "is a fancy instinct, an outlet for the overflowing activity of a creature whose wants are all provided for without any exertion on its part;" but even on this supposition there must have been some physical cause which induced the first tumbler to spend its overflowing activity in a manner unlike that of any other bird in the world. The behaviour of the ground-tumbler or Lotan of India, renders it highly probable that in this sub-breed the tumbling is due to some affection of the brain, which has been transmitted from before the year 1600 to the present day. It is necessary gently to shake these birds, or in the case of the Kalmi Lotan, to touch them on the neck with a wand, in order to make them begin rolling over backwards on the ground. This they continue to do with extraordinary rapidity, until they are utterly exhausted, or even, as some say, until they die, unless they are taken up, held in the hands, and 
soothed; and then they recover. It is well-known that certain lesions of the brin, or internal parasites, cause animals to turn incessantly round and round, either to the right or left, sometimes accompanied by a backward movement: and $I$ have just read, through the kindness of Dr. Brunton, the account given by Mr. W. J. Moore (Indian Medical Gazette, Jan. and Feb 1873) of the somewhat analogous result which followed from pricking the base of the brain of a pigeon with a needle. Birds thus treated roll over backwards in convulsions, in exactly the same manner as do the ground-tumblers; and the same effect is produced by giving them hydrocyanic acid with strychnine. One pigeon which haả its brain thus pricked recovered perfectly, but continued ever afterwards to perform summersaults like a tumbler, though not belonging to any tumbling breed. The movement appears to be of the nature of a recurrent spasm or convulsion which throws the bird backwards, as in tetanus; it then recovers its balance, and is again thrown backwards. Whether this tendency originated from some accidental injury, or, as seems more probable, from some morbid affection of the brain, cannot be told ; but at the present time the affection can hardly be called morbid in the case of common tumblers, as these birds are perfectly healthy and seem to enjoy performing their feats, or, as an old writer expresses it, "showing like footballs in the air." The habit apparently can be cortrolled to a certain extent by the will. But what more particularly concerns us is that it is strictly inherited. Young birds reared in an aviary wh ch have never seen a pigecn tumble, take to it when first let free. The habit also varies much in degree in different individuals and in different sub-breeds; and it can be greatly augmented by continued selection, as seen in the house-tumblers, which can hardly rise more than a foot or two above the ground without going head over heels in the air. Fuller details on tumbler-pigeons, may be found in my "Variation of Animals under Domestication," vol. i. pp. 150, 209.

In conclusion, from the case of neuter insects, of certain reflex actions, and of movements such as those of the tumbler-pigeon, it seems to me in the highest degree probable that many instincts have originated from modifications or variations in the brain, which we in our ignorance most improperly call spontaneous or accidental ; such variations having led, independently of experience and of habit, to changes in pre-existing instincts, or to quite new instincts, and these proving of service to the species, have been preserved and fixed, being, however, often strengthened or improved by subsequent habit.

With regard to the question of the means by which animals find their way home from a long distance, a striking account, in relation to man, will be found in the English translation of the Expedition to North Siberia, by Von Wrangell. He there describes the wonderful manner in which the natives kept a true course towards a particular spot, whilst passing for a long distance through hummocky ice, with incessant changes of direction, and with no guide in the heavens or on the frozen sea. He states (but $I$ quote only from memory of many years standing) that he, an experienced surveyor, and using, a compass, failed to do that which these savages easily effected. Yet no one will suppose that they possessed any special sense which is quite absent in us. We must bear in mind that neither a compass, nor the north star, nor any other such sign, suffices to guide a man to a particular spot through an intricate country, or through hummocky ice, when many deviations from a stright course are inevitable, unless the deviations are allowed fur, or a sort of "dead reckoning" is kept. All men are able to do this in a greater or less degree, and the natives of Siberia apparently to a wonderful extent, though probably in an unconscious manner. This is effected chiefly, no doubt, by. eyesight, but partly, perhaps, by the sense of muscular movement, in the same manner as a man with his eyes blinded can proceed (and some men much better than others) for a short distance in a nearly straight line, or turn at right angles, or back again. The manner in which the sense of direction is sometimes suddenly disarranged in very old and feeble persons, and the feeling of strong distress which, as I know, has been experienced by persons when they bave suddenly found out that they have been proceeding in a wholly unexpected and wrong direction, leads to the suspicion that some part of the brain is specialised for the function of direction. Whether animals may not possess the faculty of keeping a dead reckoning of their course in a much more perfect degree than can man; or whether this faculty may not come into play on the commencement of a journey when an animal is shut up in a basket, I will not attempt to discuss, as I have not sufficient data.

I am tempted to add one other case, but here again I am forced to quote from memory, as I have not my books at hand. Audubon kept a pinioned wild grose in confinement, and when the period of migration arrived, it became extremely restless, like all other migratory birds under similar circumstances; and at last it escaped. The poor creature then inmediately began its long journey on foot, but its sense of direction seemed to have been perverted, for instead of travelling due southward, it proceeded in exactly the wrong direction, due northward.

CHARLES DARWIN

\section{UNIVERSITY OARS}

II.

WE resume our remarks at the poins at which we left off last week, i.e. the uncomfortable one of the killed and wounded in the great annual battles on the Thames.

Of the 294 men who rowed in the 26 races taking place between the years 1829 and 1869 (both inclusive), 39 men have died, or rather we should say 40 , for one other death has occurred, apparently since the introductory portion of the work was written, and the tables in the appendix were compiled, and we are assured on the authority of elaborate statistics and the logic of averages, that, in comparison with other portions of the civil community, this is a very moderate death-rate. Of the diseases which have carried off in youth or early manhood these 40 men, we will only instance one kind, as being the only one with which boat-racing can presumably be connecied, namely consumption;, "and other diseases of the chest:" to these perhaps may be added "heart affections." Of the former there are 9, of the latter 3 , in all 12. We are assured, again, that this percentage is a mode- 